CERN-TH. 5909/90

\title{
WZ PAIR PRODUCTION AT LHC IN LEFT-RIGHT MODELS
}

\author{
D. Cocolicchio $^{a)}$, F. Feruglio ${ }^{b), c)}$, G.L. Fogli ${ }^{d), e)}$ and J. Terron $f$ )
}

\begin{abstract}
The production of $W_{R}$ and its identification through the $W Z$ decay channel is studied at LHC. The signal is characterized by a very high $Z$ transverse momentum. By considering the totally leptonic decay channel of the produced $W Z$ pair and by taking into account the possible backgrounds, we estimate that LHC with an integrated luminosity of $10^{5} \mathrm{pb}^{-1}$ will be sensitive to $W_{R}$ masses up to $2.8 \mathrm{TeV}$. A similar sensitivity is expected for SSC with $10^{4} \mathrm{pb}^{-1}$.
\end{abstract}

a) Università di Potenza, Potenza, Italy

b) Département de Physique Théorique, Université de Genève

c) On leave from Dipartimento di Fisica di Padova, I-35100 Padova, Italy

d) CERN-TH, Geneva

e) On leave from Dipartimento di Fisica di Bari and INFN, Sezione di Bari, I-70126 Bari, Italy

f) Departamento de Fisica Teorica de la Universidad Autonoma de Madrid, 28049 Madrid, Spain

CERN-TH. 5909/90

November 1990 


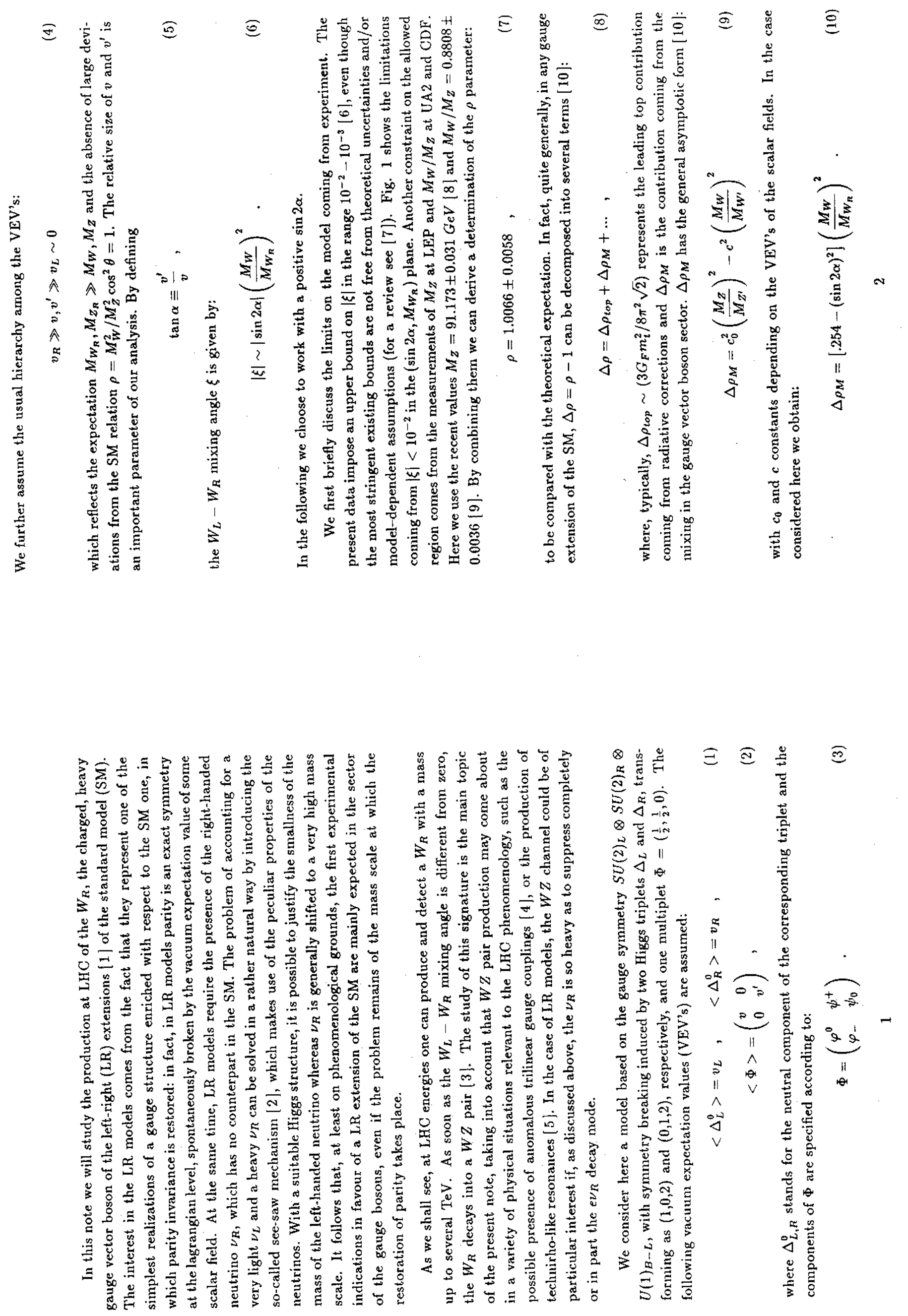




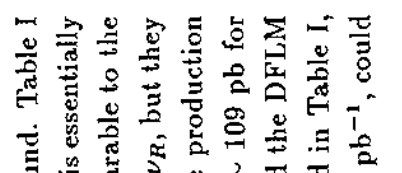

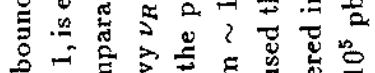

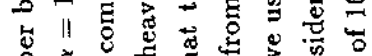

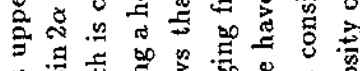

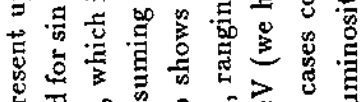

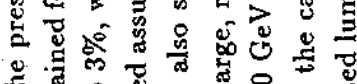

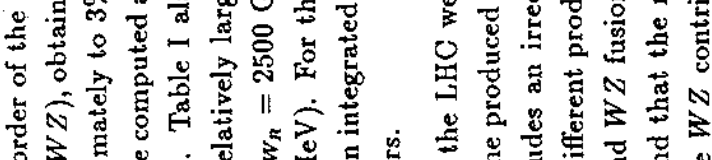

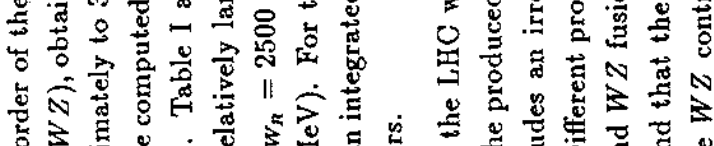

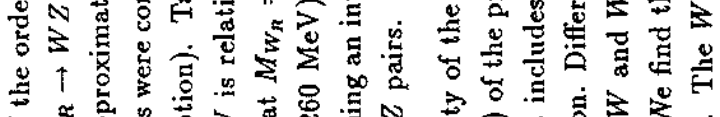

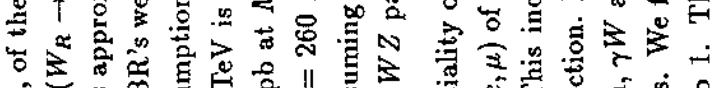

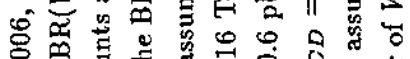

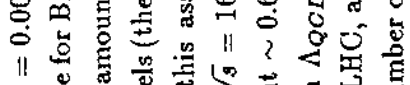

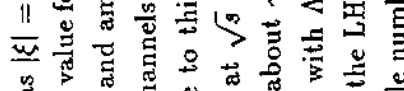

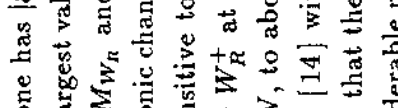

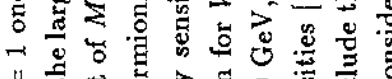

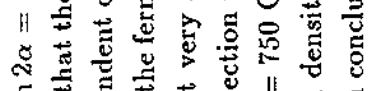

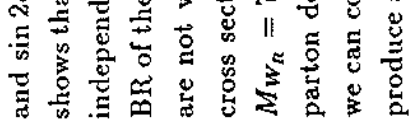

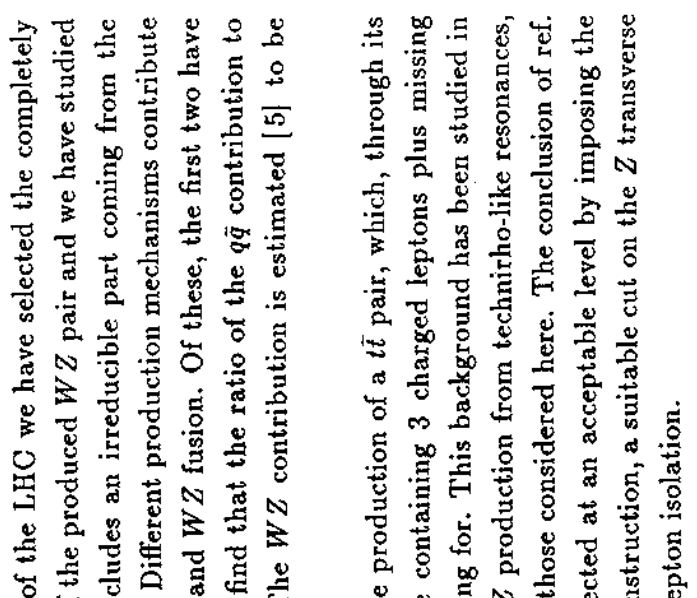

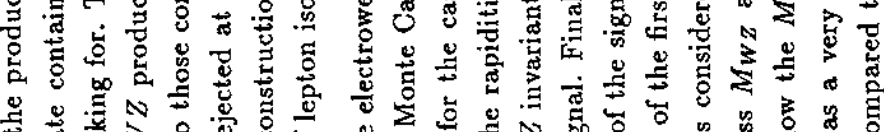

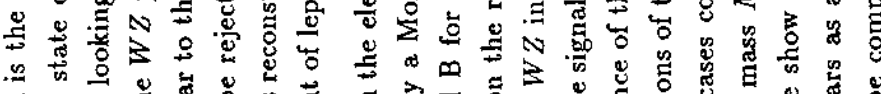

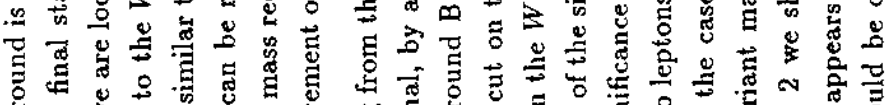

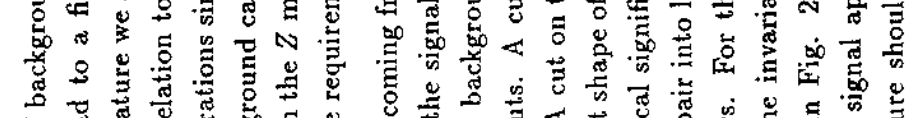

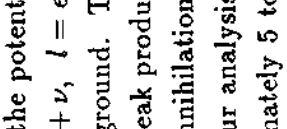

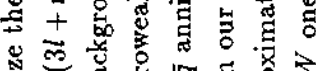

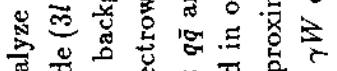

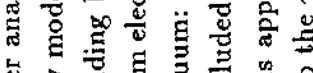

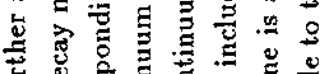

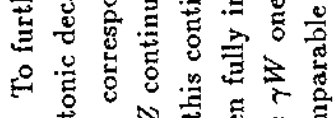

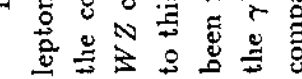

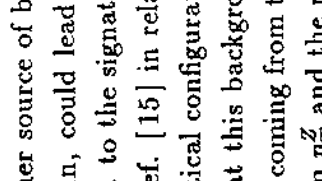

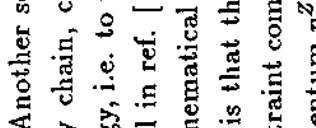

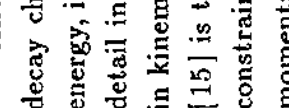

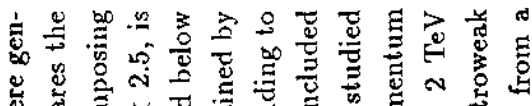

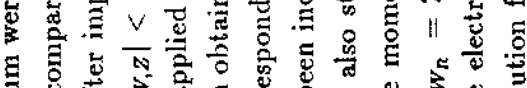

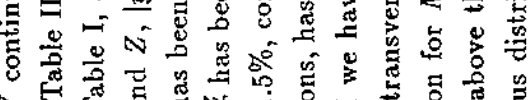

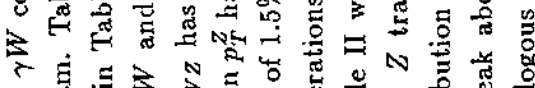

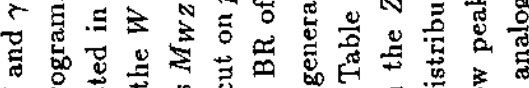
苋윯

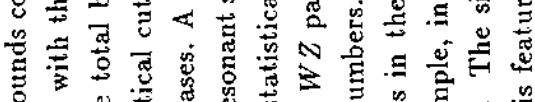

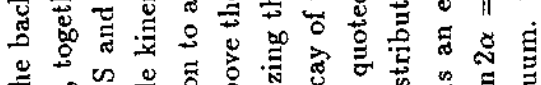

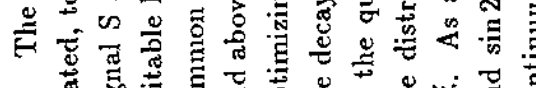

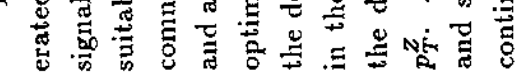

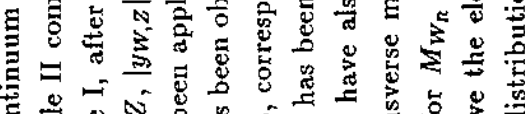

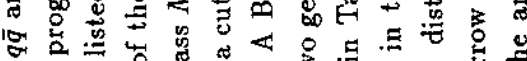

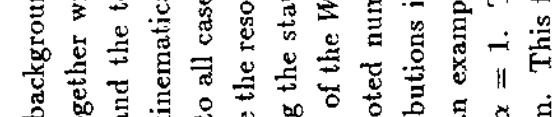

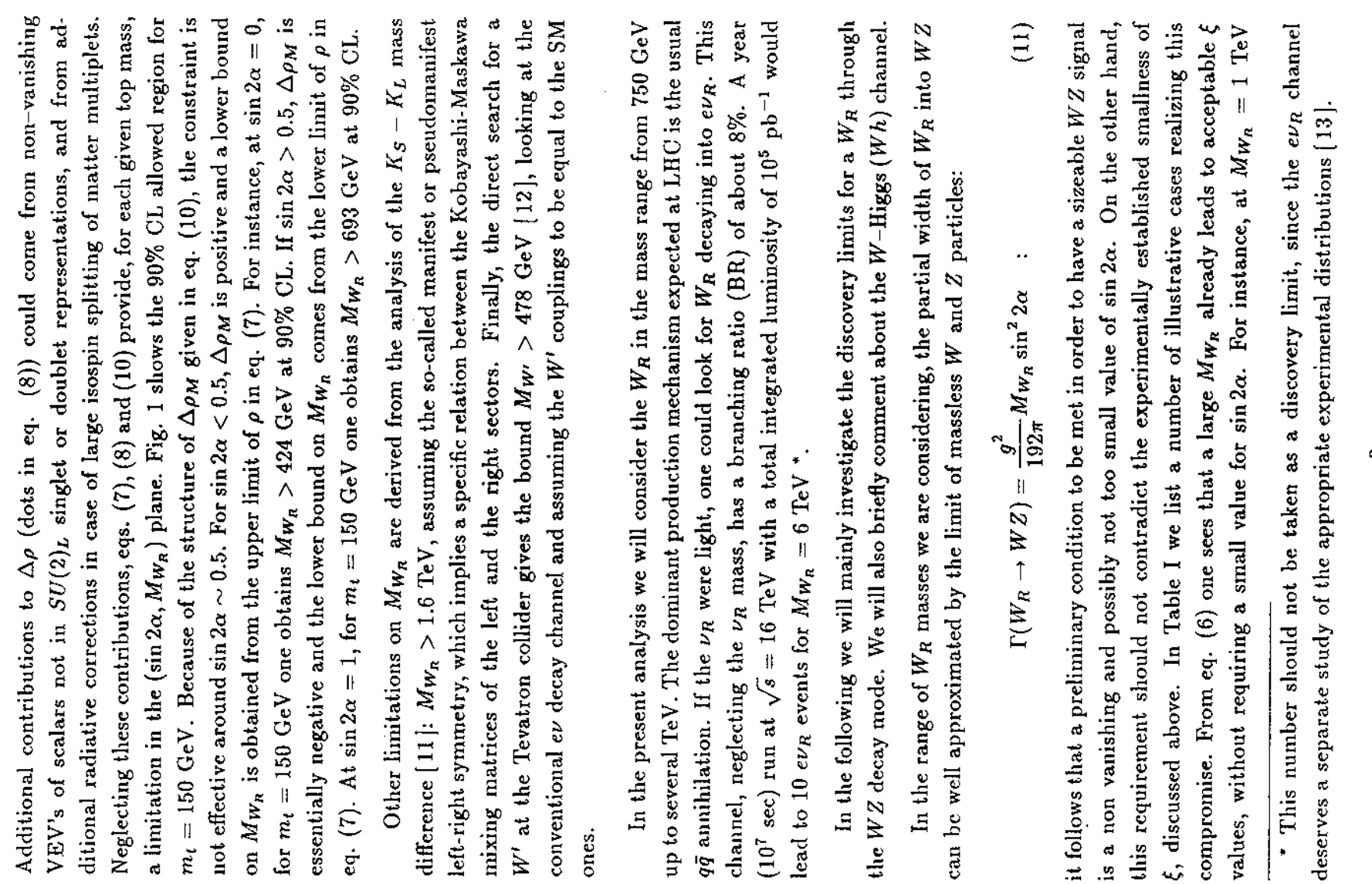




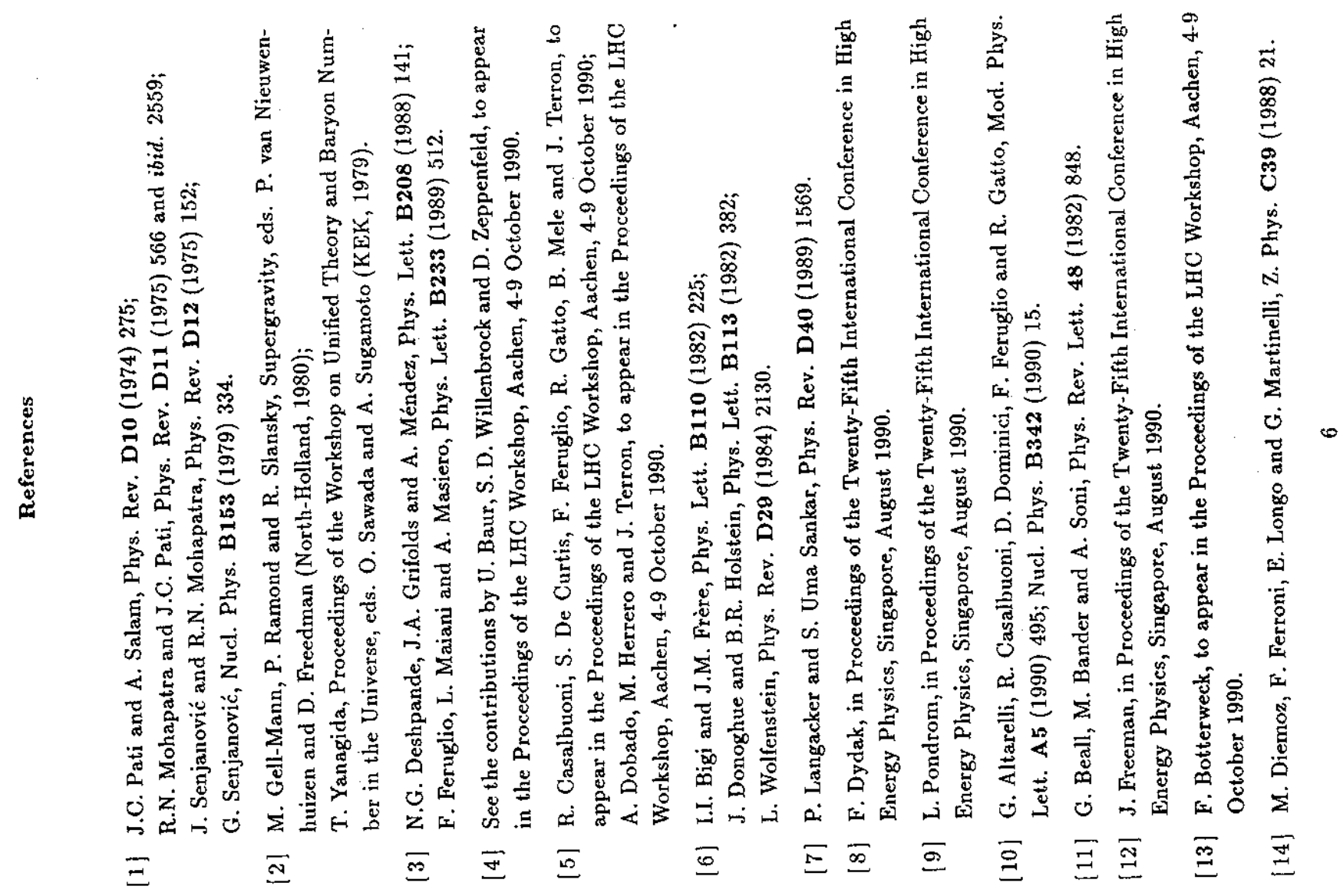

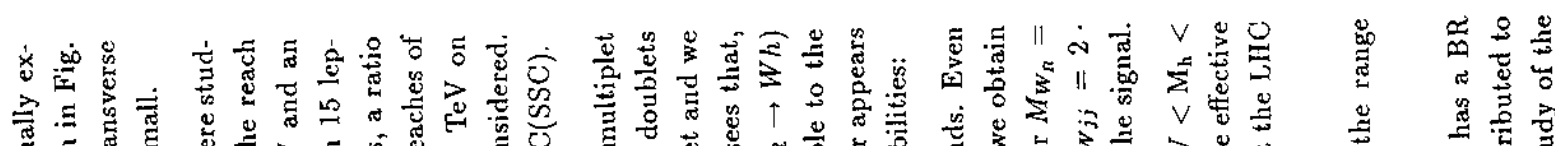

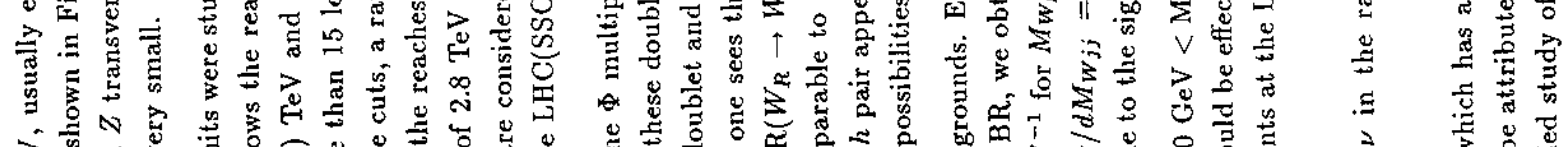

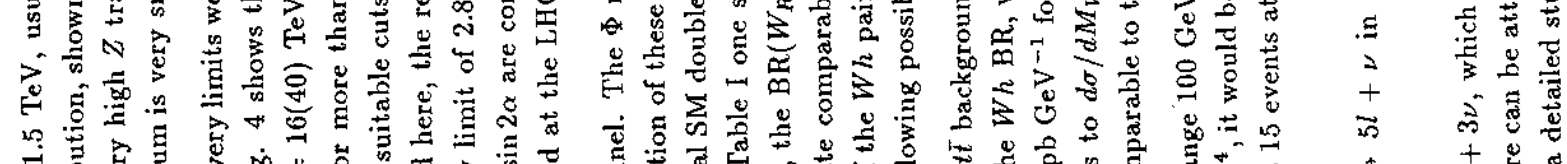
a

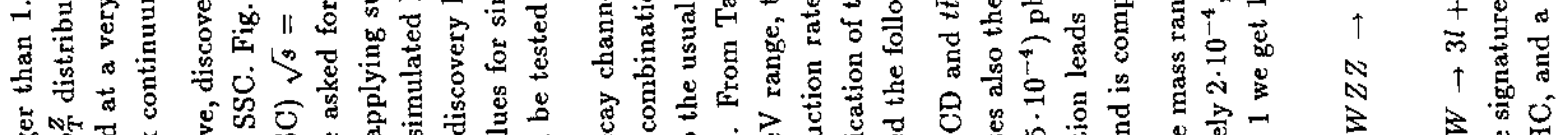

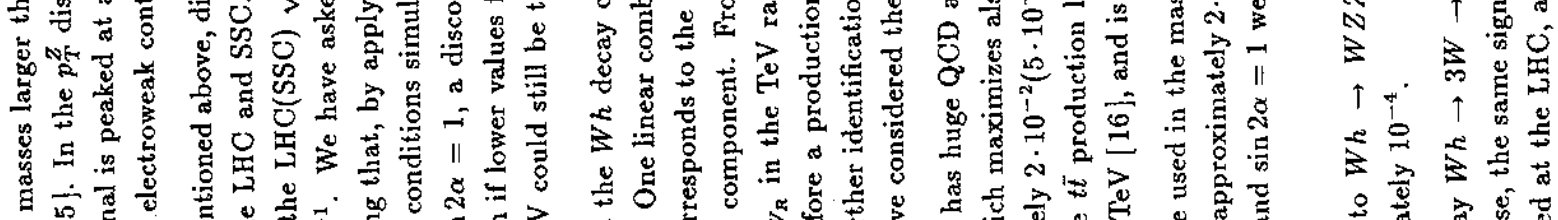

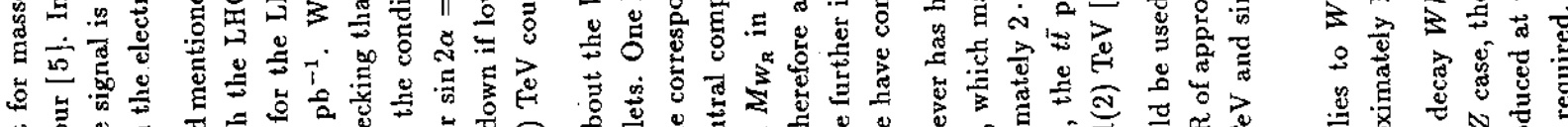

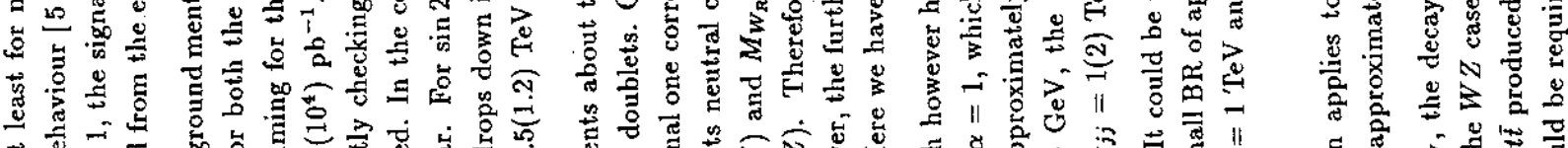

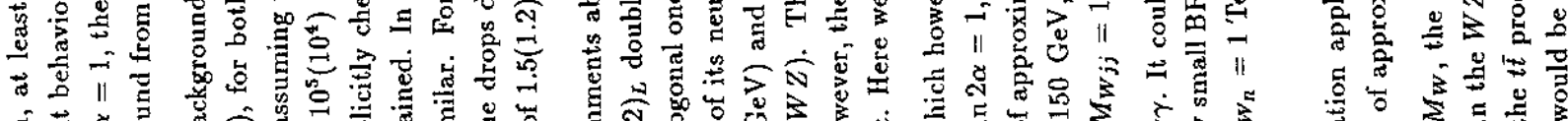

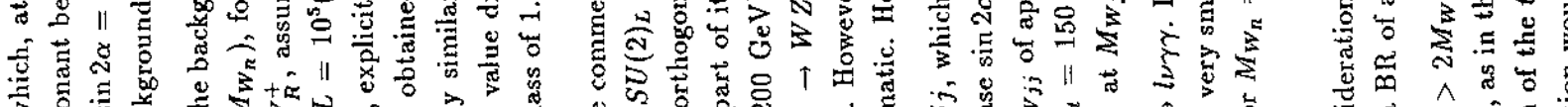

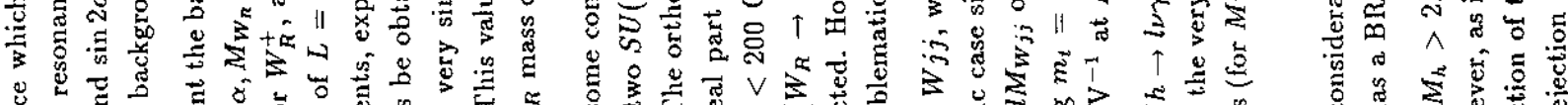

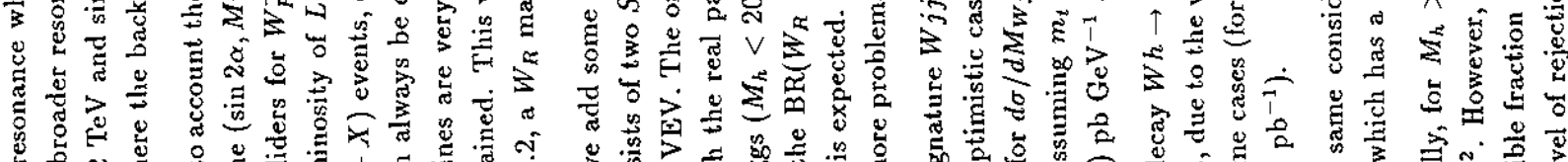

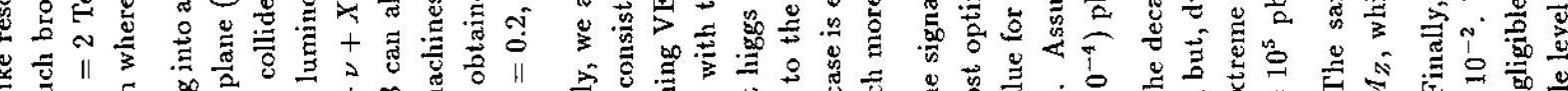

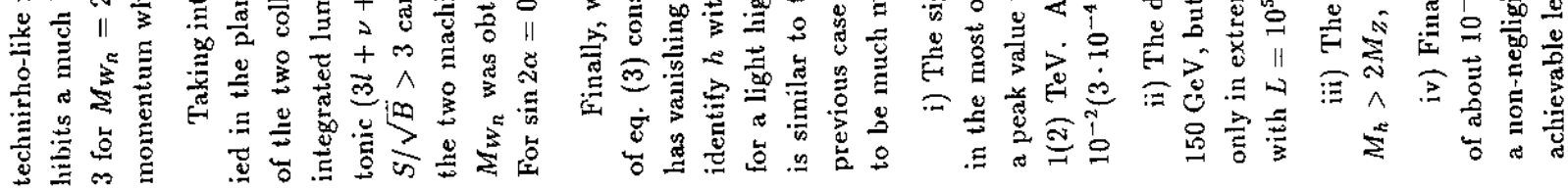




$$
\|
$$



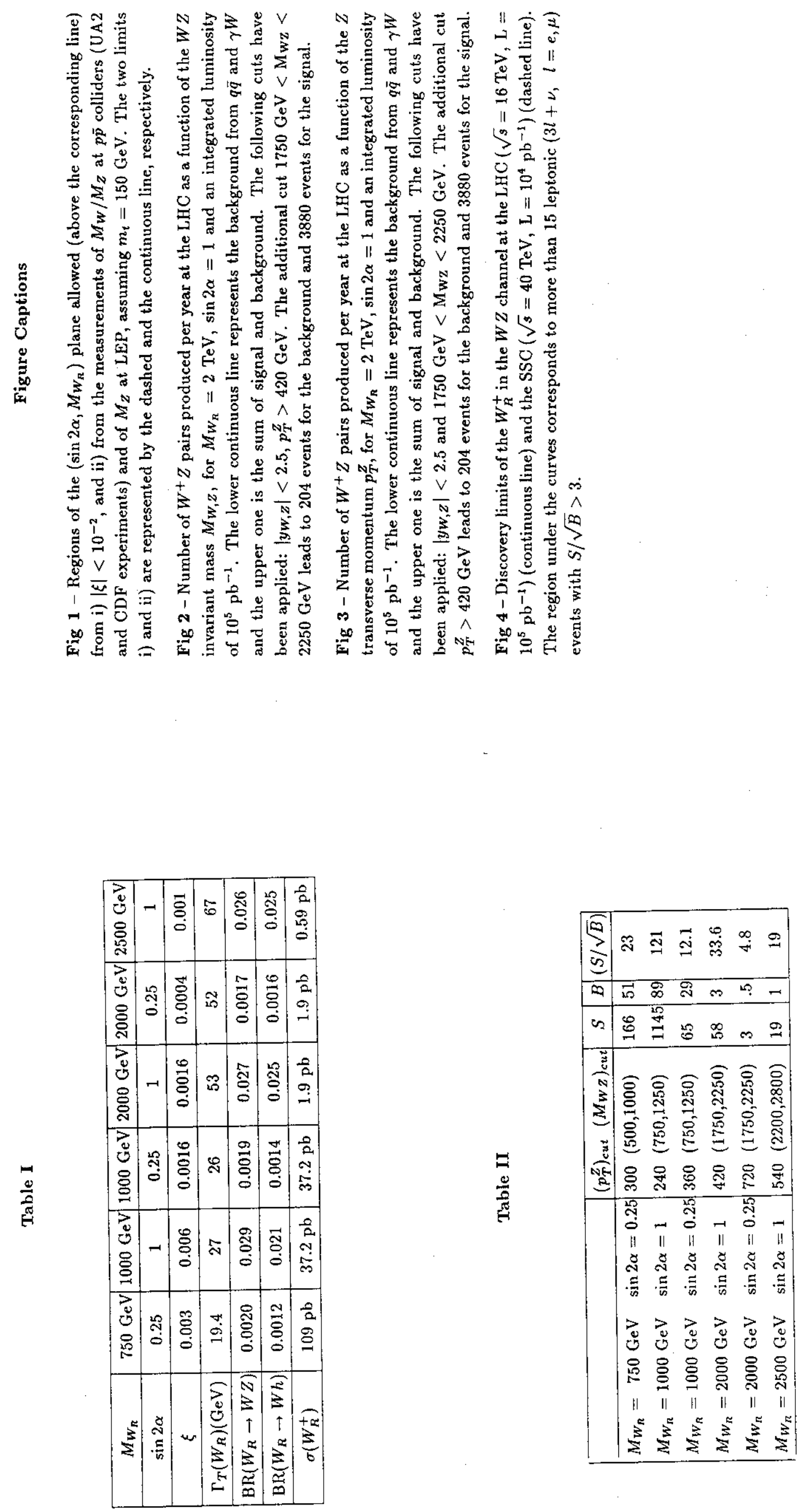


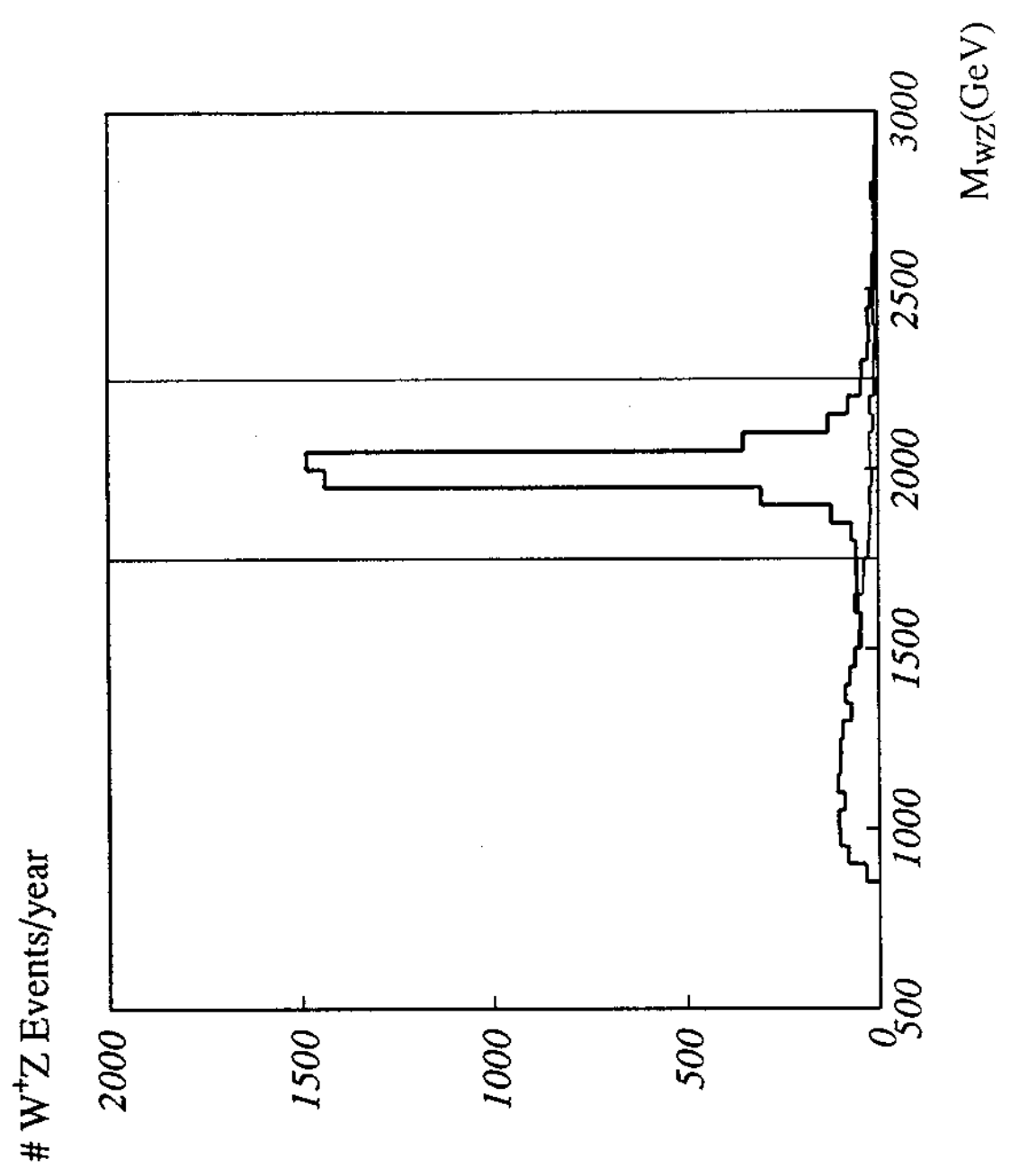

D.

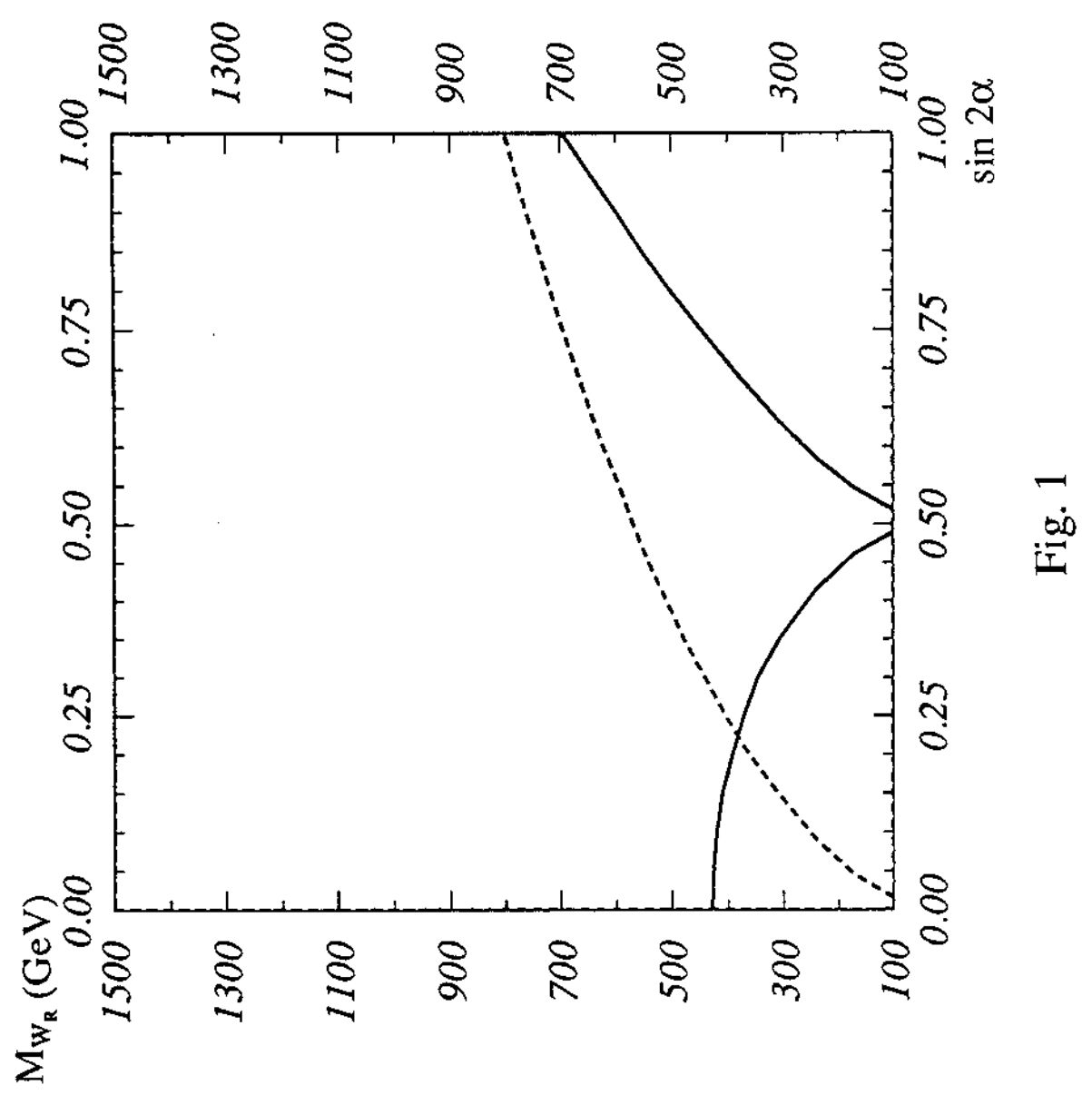



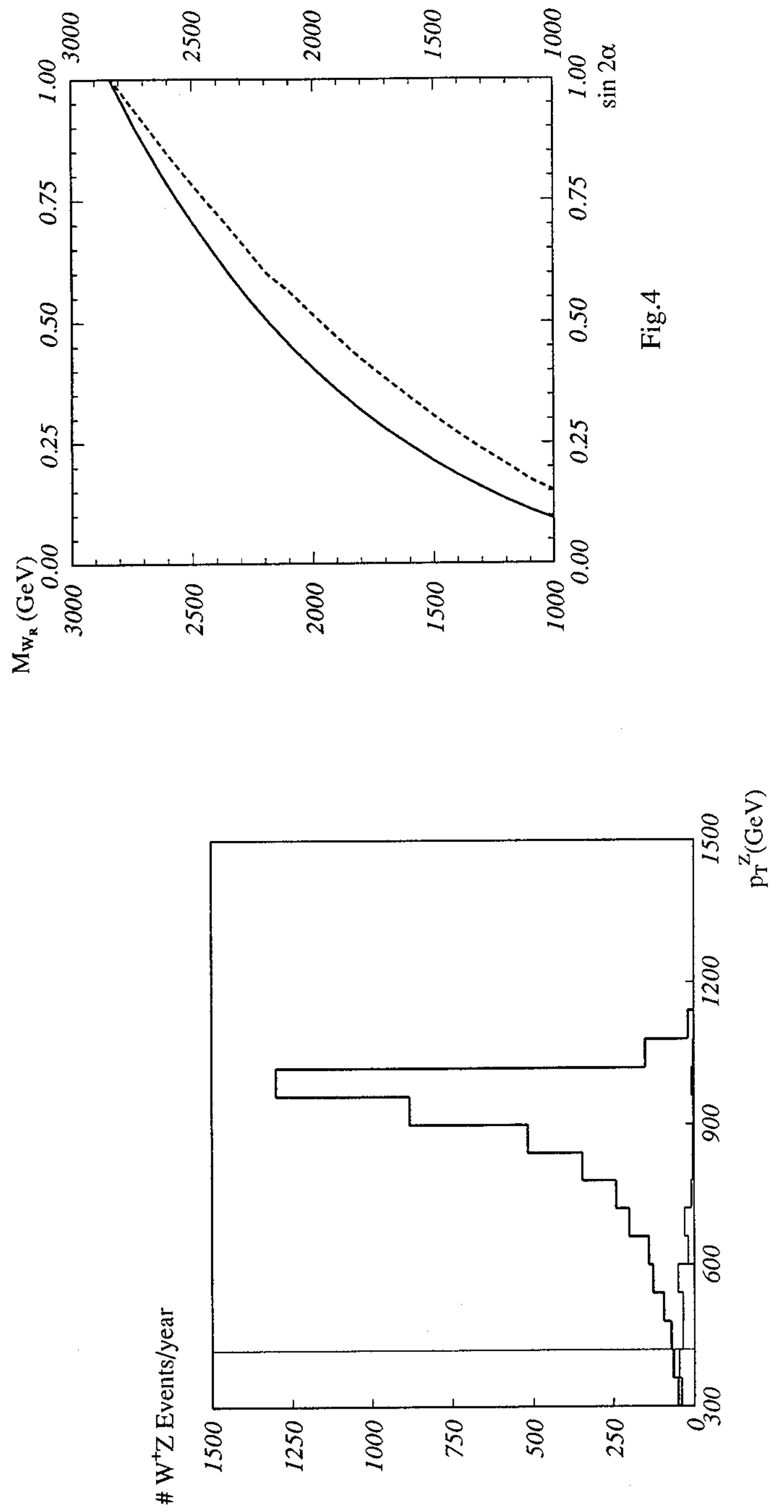

$m$ 